\title{
Swimming and Asthma: Differences between Women and Men
}

\author{
Marja Kristiina Päivinen, ${ }^{1,2}$ Kari Lasse Keskinen, ${ }^{3}$ and Heikki Olavi Tikkanen ${ }^{1,2}$ \\ ${ }^{1}$ Unit for Sport and Exercise Medicine, Institute of Clinical Medicine, University of Helsinki, Helsinki, Finland \\ ${ }^{2}$ Foundation for Sports and Exercise Medicine, Paasikivenkatu 4, 00250 Helsinki, Finland \\ ${ }^{3}$ Finnish Society of Sport Sciences Olympic Stadium, Paavo Nurmentie 1B, 00250 Helsinki, Finland
}

Correspondence should be addressed to Marja Kristiina Päivinen; marja.paivinen@hula.fi

Received 4 October 2012; Revised 18 December 2012; Accepted 9 January 2013

Academic Editor: Ting Fan Leung

Copyright (C) 2013 Marja Kristiina Päivinen et al. This is an open access article distributed under the Creative Commons Attribution License, which permits unrestricted use, distribution, and reproduction in any medium, provided the original work is properly cited.

Background and Aim. Asthma is common in endurance athletes including swimmers. Our aim was to study gender differences in asthma, allergy, and asthmatic symptoms in swimmers and investigate the effects of varying intensities of physical exercise on competitive swimmers with asthma. Methods. Three hundred highly trained swimmers (156 females and 144 males) were studied by a questionnaire. Their mean $( \pm$ SD) ages were $17 \pm 3$ and $19 \pm 3$ years, and they had training history of $7 \pm 2$ and $7 \pm 3$ years in females and males, respectively. Gender differences in asthma, allergy, and respiratory symptoms were examined. Special attention was focused on asthmatic swimmers, their allergies and respiratory symptoms during swimming at different intensities. Results. The prevalence of physician-diagnosed asthma was 19\% for females and males. No gender differences in asthma or respiratory symptoms were found. Males reported allergies significantly more often than females $(P=0.007)$. Gender difference was found in respiratory symptoms among swimmers with physician-diagnosed asthma because females reported symptoms significantly more often $(P=0.017)$ than males. Asthmatic females also reported symptoms significantly more often at moderate intensity swimming $(P=0.003)$ than males especially for coughing. Discussion. Gender difference in prevalence of asthma was not found in swimmers. However, allergy was reported significantly more by male swimmers. Male swimmers with asthma reported significantly more cases having family history of asthma, which may be a sign of selection of asthma-friendly sport. Moderate intensity swimming seemed to induce significantly more symptoms especially coughing in asthmatic females.

\section{Introduction}

The prevalence of asthma among Finnish competitive swimmers is higher than that in general population which is typical in endurance sports $[1,2]$. Gender differences in prevalence of asthma have been found in general population. Asthma and especially the nonallergic asthma were more prevalent in women than men [3,4]. In Finnish general population asthma was mostly associated with family history of asthma, allergy, smoking, and obesity [4]. General population is different than competitive swimmers population, because weight gaining, aging, and smoking-related factors are missing as competitive swimmers are mainly fairly young, with normal BMI and nonsmoking.

Intensity, duration, and type of exercise are known to have an effect on the severity of the respiratory symptoms [5]. For example, at the same exercise intensity level, asthmatic symptoms are fewer and milder in swimming than in running or cycling [6,7]. That may affect the selection of sport in persons who have sensitivity in lung function. In all endurance sports like swimming as well, the demands for lung function are high due to prolonged workouts in high intensities.

In asthmatics physical exercise in the intensity level of $90 \%$ of maximum heart rate for 6-8 minutes typically causes the asthmatic symptoms [8]. In a previous study by Päivinen et al. (2010) [9], reported respiratory symptoms in five different swimming intensities were studied. To our knowledge the gender differences in asthmatic symptoms in different intensities in swimmers with physician-diagnosed asthma are not studied before.

The aim of the study was to examine gender differences among competitive swimmers and especially swimmers with asthma. The focus was to concentrate on comparing allergies, family history of asthma and allergies, and the respiratory symptoms in different intensities in physical 


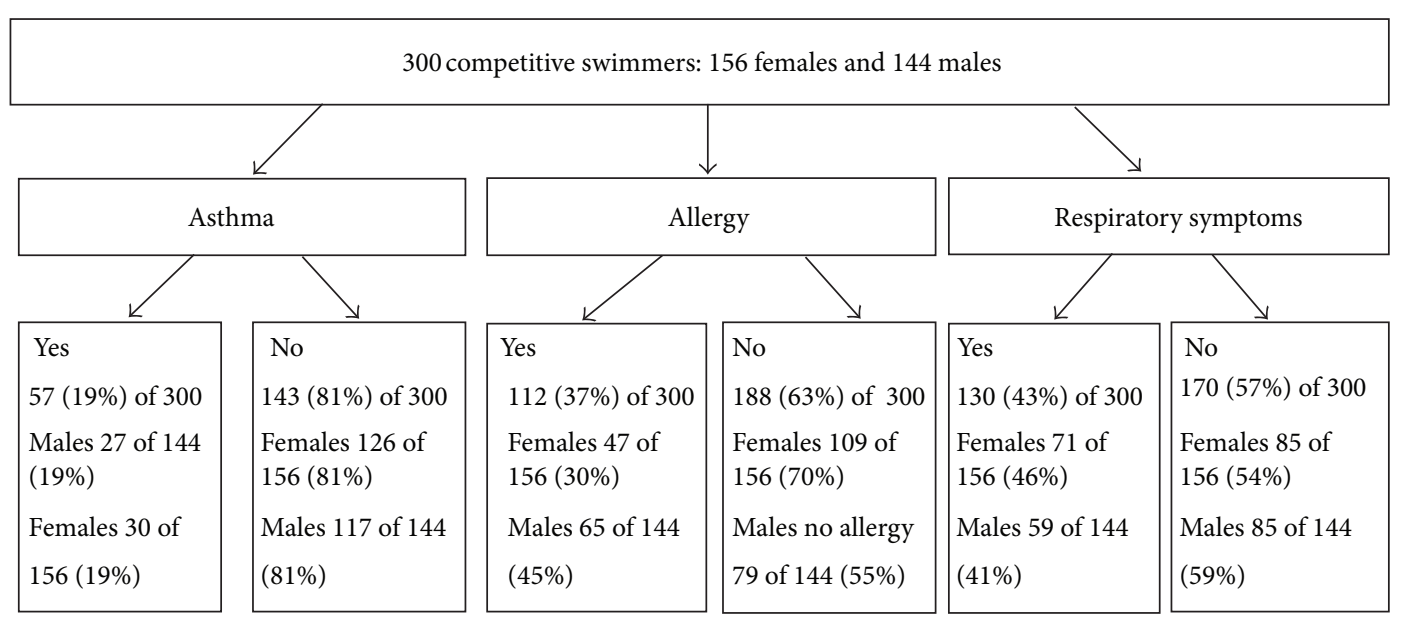

FIGURE 1: The prevalence of physician-diagnosed asthma, physician-diagnosed allergy, and reported respiratory symptoms in 300 competitive swimmers.

TABLE 1: Gender differences in 57 swimmers with physician-diagnosed asthma out of 300 elite competitive swimmers.

\begin{tabular}{|c|c|c|c|}
\hline Physician-diagnosed asthma & Women 30 & Men 27 & $P$ value \\
\hline Age (mean SD), years & $17 \pm 3$ & $19 \pm 3$ & $<0.001^{*}$ \\
\hline Age of the asthma diagnosis (mean SD), years & $13 \pm 3$ & $9 \pm 6$ & $<0.001^{*}$ \\
\hline Allergy & $20 / 30$ & $21 / 27$ & 0.462 \\
\hline Reported respiratory symptoms & $29 / 30$ & $20 / 27$ & $0.014^{*}$ \\
\hline Family history of asthma & $5 / 30$ & $14 / 27$ & $0.005^{*}$ \\
\hline Family history of allergy & $16 / 30$ & $17 / 27$ & 0.462 \\
\hline
\end{tabular}

* Significant difference.

exercise between female and male swimmers. As swimming has been suggested to be a suitable physical exercise therapy for persons with asthma, this study examined swimming special features related to asthma and allergy to obtain further knowledge of the differences between female and male swimmers.

\section{Methods}

Three hundred Finnish competitive swimmers, 156 females and 144 males, were studied by a questionnaire. Studied swimmers were selected for the study according to the sufficient training history and performance level of qualification for national championships. Swimmers were at mean SD age of (mean SD) $18 \pm 3$ years, females $17 \pm 3$ and males $19 \pm 3$ years. Swimming training history was mean $7 \pm 2$ years in females and $7 \pm 3$ years in males. Weekly training hours were on the average $16 \pm 4$ hours in females and $16 \pm 3$ hours in males.

Gender differences of prevalence of physician-diagnosed asthma, allergy, and respiratory symptoms were studied first. Then, the swimmers reporting physician-diagnosed asthma were taken into further examination. The differences were studied with the chi-square test and considered significant when $P$ value was $<0.05$. Swimmers with physiciandiagnosed asthma were subjected to further detailed analysis.
Wilcoxon sum rank test was used to compare the ages of the onset of asthma diagnosis in asthmatic swimmers.

The questionnaire consisted of questions concerning basic information, training history, asthma, allergy, family history of asthma and allergy, and respiratory symptoms (shortness of breath, wheezing, coughing, and mucous production) during swimming. Five (I-V) different swimming intensities as presented, for example, by Keskinen 1993 [10] were recorded. Intensity zone I represented easy endurance swimming, zone II was moderate endurance exercise between aerobic and anaerobic thresholds, zone III was a swimming pace between the anaerobic threshold and the minimal velocity to achieve maximal oxygen uptake, zone IV velocity was higher than zone III, with a competitionspecific race pace maximizing muscle lactic acid production, and zone $\mathrm{V}$ was all-out sprinting [10]. The questionnaire has been applied earlier for swimmers [9].

In asthmatic swimmers, physician-diagnosed allergy, family history of asthma and allergy, and reported asthmatic symptoms were studied in different training intensities. The analysis describing symptoms in five different training intensities was previously used by Leynaert et al. 2012 [3]. Asthmatic symptoms wheezing, coughing, shortness of breath, and mucous production during swimming at five (I-V) different exercise intensities [10].

The ethics committee of the Hospital District of Helsinki and Uusimaa approved the study protocol. 
TABLE 2: Gender differences in types of allergy and allergic reaction in the asthmatic swimmers.

\begin{tabular}{lccc}
\hline Physician-diagnosed asthma & Women 30 & Men 27 & $P$ value \\
\hline Animal allergy & $19 / 30$ & $16 / 27$ & $17 / 27$ \\
Pollen allergy & $13 / 30$ & $11 / 27$ & 0.696 \\
Home dust allergy & $6 / 30$ & $7 / 27$ & 0.87 \\
Food allergy & $8 / 30$ & $10 / 27$ & 0.949 \\
Allergic reaction in eyes & $12 / 30$ & $12 / 27$ & 0.819 \\
Allergic reaction as runny nose & $17 / 30$ & $6 / 27$ & 0.357 \\
Allergic reaction on skin & $4 / 30$ & $7 / 27$ & 0.378 \\
Other types of allergic reactions & $7 / 30$ & 0.820 \\
\hline
\end{tabular}

* Significant difference.

TABLE 3: Gender differences of reported respiratory symptoms at different training intensities in asthmatic swimmers.

\begin{tabular}{lccc}
\hline Reported symptoms at swimming intensity & Women with asthma & Men with asthma & $P$ value \\
\hline Easy: I & $8 / 30$ & $4 / 27$ & $5 / 27$ \\
Moderate: II & $17 / 30$ & $13 / 27$ & 0.273 \\
Hard: III & $13 / 30$ & $12 / 27$ & 0.716 \\
Very hard: IV & $16 / 30$ & $7 / 27$ & 0.503 \\
Maximum sprint & $14 / 30$ & 0.105 \\
\hline
\end{tabular}

*Significant difference.

\section{Results}

Physician-diagnosed asthma prevalence was $19 \%$ in both females and males. No gender differences in prevalence of physician-diagnosed asthma and reported respiratory symptoms were found. Male swimmers reported significantly more physician-diagnosed allergy $(P=0.007)$ than females. No gender differences were found when reporting respiratory symptoms in swimming in the whole 300 swimmers population (Figure 1).

However among swimmers with asthma, gender differences were found in the age of onset of asthma, when reporting respiratory symptoms, and in the family history of asthma (Table 1). Females reported significantly more symptoms especially at moderate intensity swimming (Table 3). No gender differences were found in allergies in swimmers with physician-diagnosed asthma (Table 2).

In swimmers with asthma, gender difference was observed as females reported more symptoms at the intensity II: moderate endurance training (Figure 2). Female swimmers with asthma reported significantly more coughing and mucous production at moderate swimming intensity. In addition female swimmers with asthma reported significantly more coughing in every intensity level than male swimmers with asthma (Table 4).

\section{Discussion}

Among the studied 300 swimmers, no gender difference in prevalence of asthma was found, unlike in the previous studies in Finnish general population [4]. This finding may be explained by selection of swimming in many ways. Athletes with asthma may choose swimming because it is a low asthmogenic sport [6, 7], and in spite of asthma many athletes may achieve international top level [11]. The studied competitive swimmers had normal weight and were nonsmoking young adults, so the reasons mostly related to gender differences in general population in females were excluded: obesity and hormonal changes in the age of 40-60 [12].

Significant gender differences were found in physiciandiagnosed allergy. Male swimmers reported more allergies than females. That may be linked to the fact that swimming is a low-symptom-causing sport and therefore especially chosen by males with allergy. In swimmers with asthma no gender differences in reported physician-diagnosed allergy were found. That was inconsistent with previous studies on general population where nonallergic asthma was found more in females [3].

Among swimmers with asthma gender difference was significant in the age of the onset of asthma (Table 1) as male swimmers had asthma in younger age than females. Results show that male swimmers mainly had asthma before swimming training had started and females later during swimming career, almost in puberty. Male swimmers reported significantly more often family history of asthma than asthmatic females. Therefore, fewer cases having family history of asthma and later onset of asthma may be related to higher amount of reported respiratory symptoms during swimming in asthmatic female swimmers.

In previous studies $[2,9]$ family history of asthma and allergies have been linked to asthma in athletes. Also in this study only two of 57 swimmers with asthma (0.07\% of 300 studied swimmers) reported asthma without any allergy or family history of asthma.

Gender differences in swimmers with physician-diagnosed asthma were found in reported respiratory symptoms 
TABLE 4: Gender differences in reported respiratory symptoms: shortness of breath, wheezing, coughing, and mucous production at different swimming intensities in 30 asthmatic female swimmers (F) and 27 asthmatic male swimmers (M).

\begin{tabular}{lcccccccccccc}
\hline & \multicolumn{3}{c}{ Shortness of breath } & \multicolumn{3}{c}{ Wheezing } & \multicolumn{3}{c}{ Coughing } & \multicolumn{3}{c}{ Mucous production } \\
& $\mathrm{F}$ & $\mathrm{M}$ & $P$ value & $\mathrm{F}$ & $\mathrm{M}$ & $P$ value & $\mathrm{F}$ & $\mathrm{M}$ & $P$ value & $\mathrm{F}$ & $\mathrm{M}$ & $P$ value \\
\hline Easy & $3 / 30$ & $2 / 27$ & 0.730 & $0 / 30$ & $3 / 27$ & 0.061 & $2 / 30$ & $1 / 27$ & 0.913 & $1 / 30$ & $3 / 27$ & 0.251 \\
Moderate & $9 / 30$ & $3 / 27$ & 0.081 & $3 / 30$ & $3 / 27$ & 0.891 & $12 / 30$ & $1 / 27$ & $0.001^{*}$ & $14 / 30$ & $4 / 27$ & $0.010^{*}$ \\
Hard & $18 / 30$ & $11 / 27$ & 0.146 & $14 / 30$ & $10 / 27$ & 0.462 & $18 / 30$ & $4 / 27$ & $<0.001^{*}$ & $14 / 30$ & $6 / 27$ & 0.054 \\
Very hard & $18 / 30$ & $11 / 27$ & 0.146 & $15 / 30$ & $8 / 27$ & 0.118 & $18 / 30$ & $4 / 27$ & $0.001^{*}$ & $12 / 30$ & $6 / 27$ & 0.149 \\
Max sprint & $6 / 30$ & $7 / 27$ & 0.594 & $9 / 30$ & $3 / 27$ & 0.081 & $12 / 30$ & $3 / 27$ & $0.013^{*}$ & $1 / 30$ & $3 / 27$ & 0.251 \\
\hline
\end{tabular}

F: females, M: males.

*Significant difference.
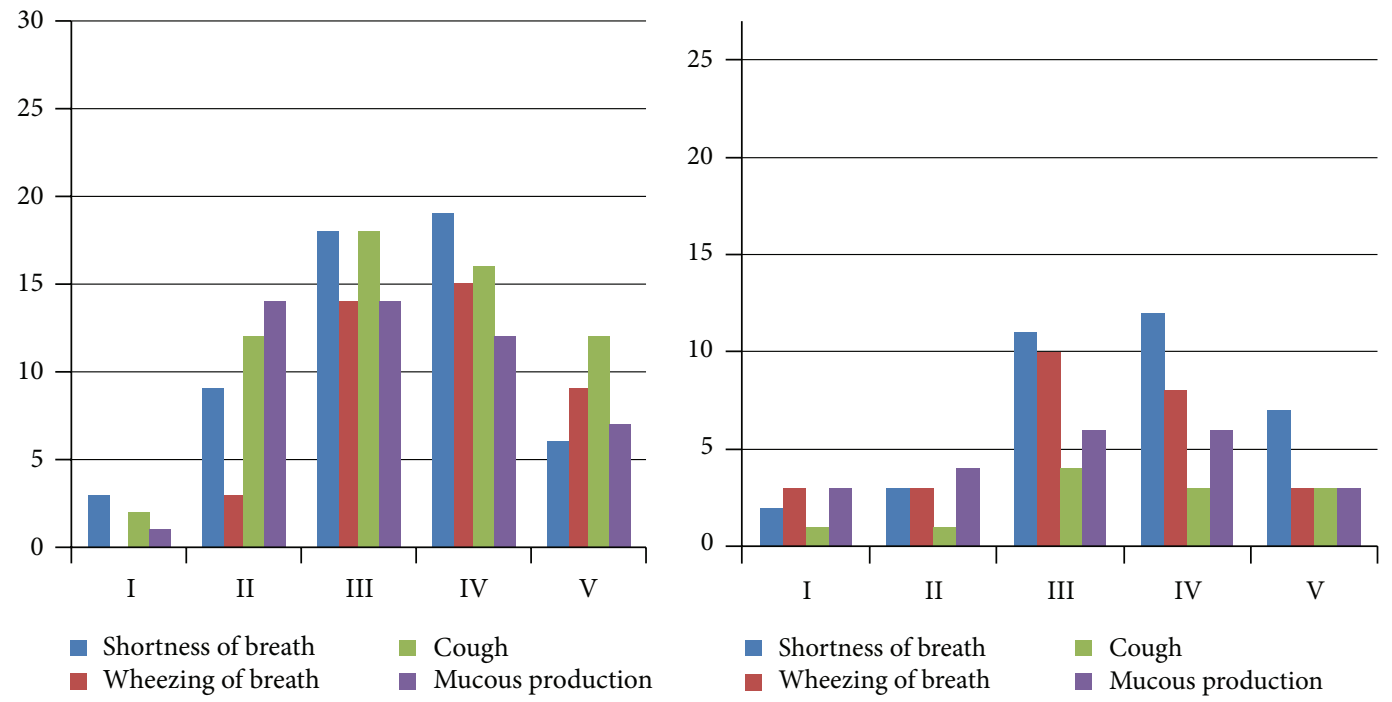

FIGURE 2: Reported respiratory symptoms at different swimming intensities (I: easy, II: moderate, III: hard, IV: very hard, and V: maximum sprint) in 30 asthmatic female swimmers on the left panel and in 27 asthmatic male swimmers.

during swimming. Interestingly, coughing, which in previous studies has been reported to be the most common respiratory symptom in athletes $[5,13]$, was frequently reported in asthmatic female swimmers but not in males. In a study by Heir (1994) [14] all but coughing was more frequent in athletes with asthma, which is consistent with the result in this study on asthmatic male swimmers [14]. The results showed, surprisingly, that female swimmers with asthma reported significantly more often symptoms in moderate intensity than males (Figure 2 and Table 4). This observation may have been linked to the asthma background as the females had their asthma diagnosis mainly during swimming career. It may also be influenced by smaller lungs related to body size in females than males. This may also cause gender difference in the ventilation dynamics during swimming and the efficiency in body-size-related work load in physical exercise on land. With different ventilation dynamics in females and males, moderate intensity swimming may be different.

\section{Conclusions}

According to asthma allergy and respiratory symptoms gender differences in competitive swimmers vary from general population. In swimmers with physician-diagnosed asthma gender differences were seen in reported asthmatic symptoms especially in moderate intensity and coughing.

\section{Acknowledgments}

The authors thank the Finnish Respiratory Disease Research Foundation, the Finnish Allergy Research Foundation, the Finnish Athletics Research Foundation, Ida Montin Foundation, and the Ministry of Health and Social Affairs of Finland for funding this study. They also thank the swimming clubs Helsingfors Simsallskap HSS and CETUS for their cooperation in this study.

\section{References}

[1] I. J. Helenius, H. O. Tikkanen, and T. Haahtela, "Association between type of training and risk of asthma in elite athletes," Thorax, vol. 52, no. 2, pp. 157-160, 1997.

[2] H. O. Tikkanen and I. Helenius, "Asthma in runners," British Medical Journal, vol. 309, no. 6961, p. 1087, 1994.

[3] B. Leynaert, J. Sunyer, R. Garcia-Esteban et al., "Gender differences in prevalence, diagnosis and incidence of allergic and 
non-allergic asthma: a population-based cohort," Thorax, vol. 67, no. 7, pp. 625-631, 2012.

[4] P. Pallasaho, B. Lundbäck, S. L. Läspä et al., "Increasing prevalence of asthma but not of chronic bronchitis in Finland? Report from the FinEsS-Helsinki study," Respiratory Medicine, vol. 93, no. 11, pp. 798-809, 1999.

[5] T. Heir and S. Oseid, "Self-reported asthma and exerciseinduced asthma symptoms in high-level competitive crosscountry skiers," Scandinavian Journal of Medicine \& Science in Sports, vol. 4, no. 2, pp. 128-133, 1994.

[6] K. D. Fitch and S. Godfrey, "Asthma and athletic performance," Journal of the American Medical Association, vol. 236, no. 2, pp. 152-157, 1976.

[7] E. Bar-Yishay, I. Gur, and O. Inbar, "Differences between swimming and running as stimuli for exercise-induced asthma," European Journal of Applied Physiology and Occupational Physiology, vol. 48, no. 3, pp. 387-397, 1982.

[8] S. D. Anderson, N. M. Connolly, and S. Godfrey, "Comparison of bronchoconstriction induced by cycling and running," Thorax, vol. 26, no. 4, pp. 396-401, 1971.

[9] M. K. Päivinen, K. L. Keskinen, and H. O. Tikkanen, "Swimming and asthma: factors underlying respiratory symptoms in competitive swimmers," Clinical Respiratory Journal, vol. 4, no. 2, pp. 97-103, 2010.

[10] K. L. Keskinen, Stroking Characteristics of Front Crawl Swimming, University of Jyväskylä, Jyväskylä, Finland, 1993.

[11] J. M. Weiler, T. Layton, and M. Hunt, "Asthma in United States olympic athletes who participated in the 1996 summer games," Journal of Allergy and Clinical Immunology, vol. 102, no. 5, pp. 722-726, 1998.

[12] M. C. Moreno, L. López-Viña, M. García-Salmones, C. C. Serrano, J. J. Esteban, and M. T. M. Prieto, "Factors related with the higher percentage of hospitalizations due to asthma amongst women: the FRIAM study," Archivos de Bronconeumología, vol. 48, no. 7, pp. 234-239, 2012.

[13] K. W. Rundell, J. Im, L. B. Mayers, R. L. Wilber, L. Szmedra, and H. R. Schmitz, "Self-reported symptoms and exercise-induced asthma in the elite athlete," Medicine and Science in Sports and Exercise, vol. 33, no. 2, pp. 208-213, 2001.

[14] T. Heir, "Longitudinal variations in bronchial responsiveness in cross-country skiers and control subjects," Scandinavian Journal of Medicine \& Science in Sports, vol. 4, no. 2, pp. 134-139, 1994. 


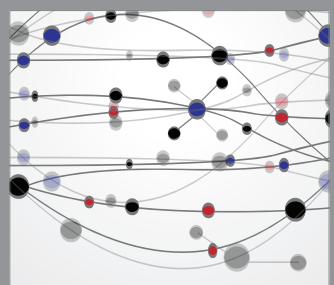

The Scientific World Journal
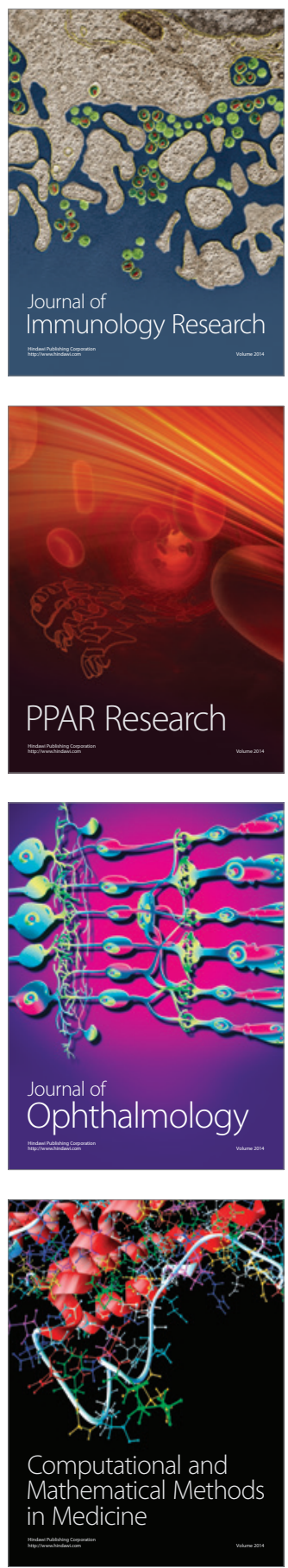

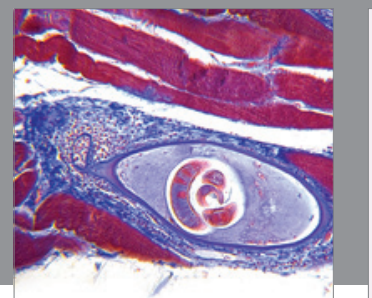

Gastroenterology

Research and Practice
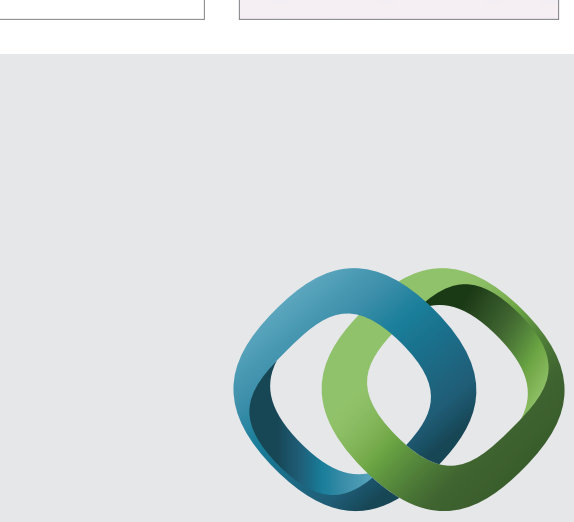

\section{Hindawi}

Submit your manuscripts at

http://www.hindawi.com
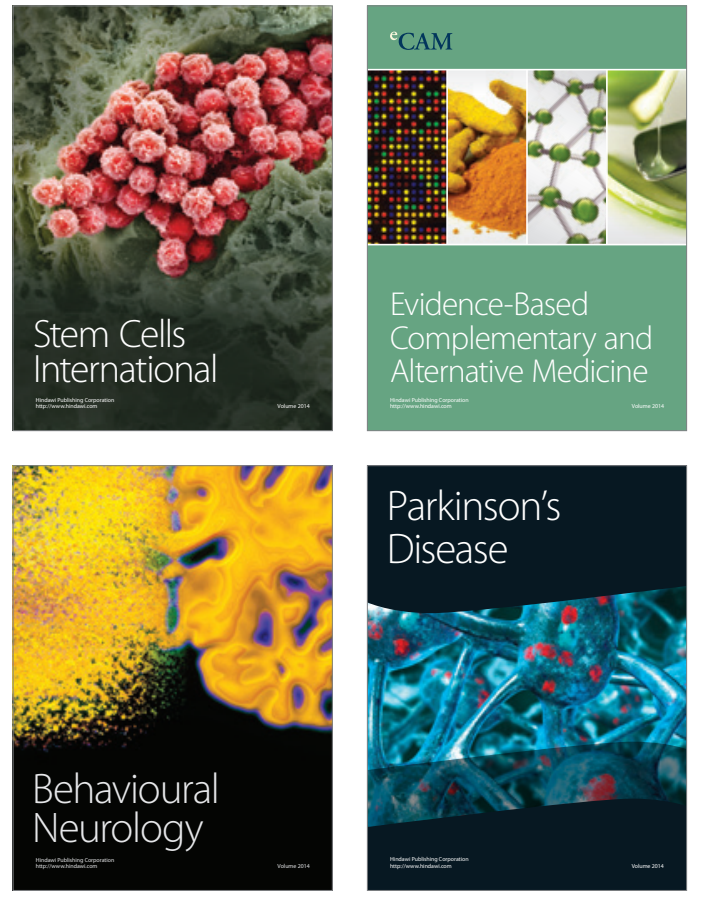
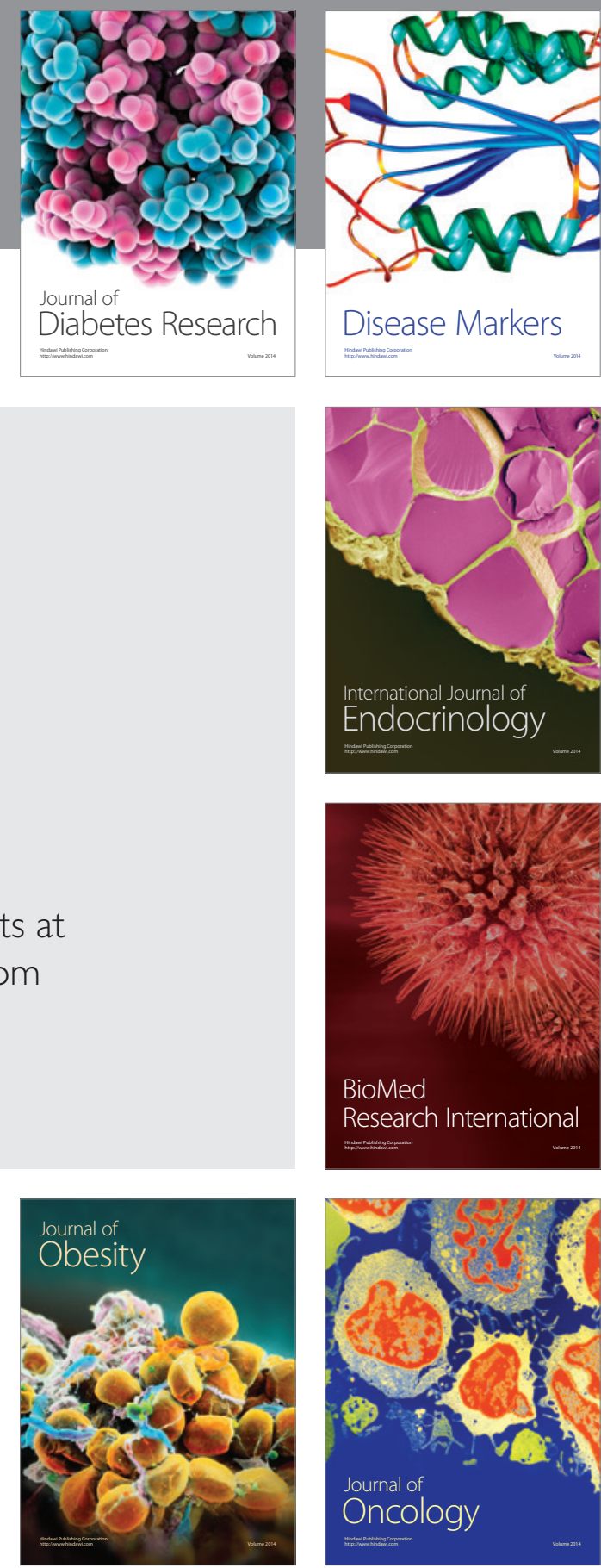

Disease Markers
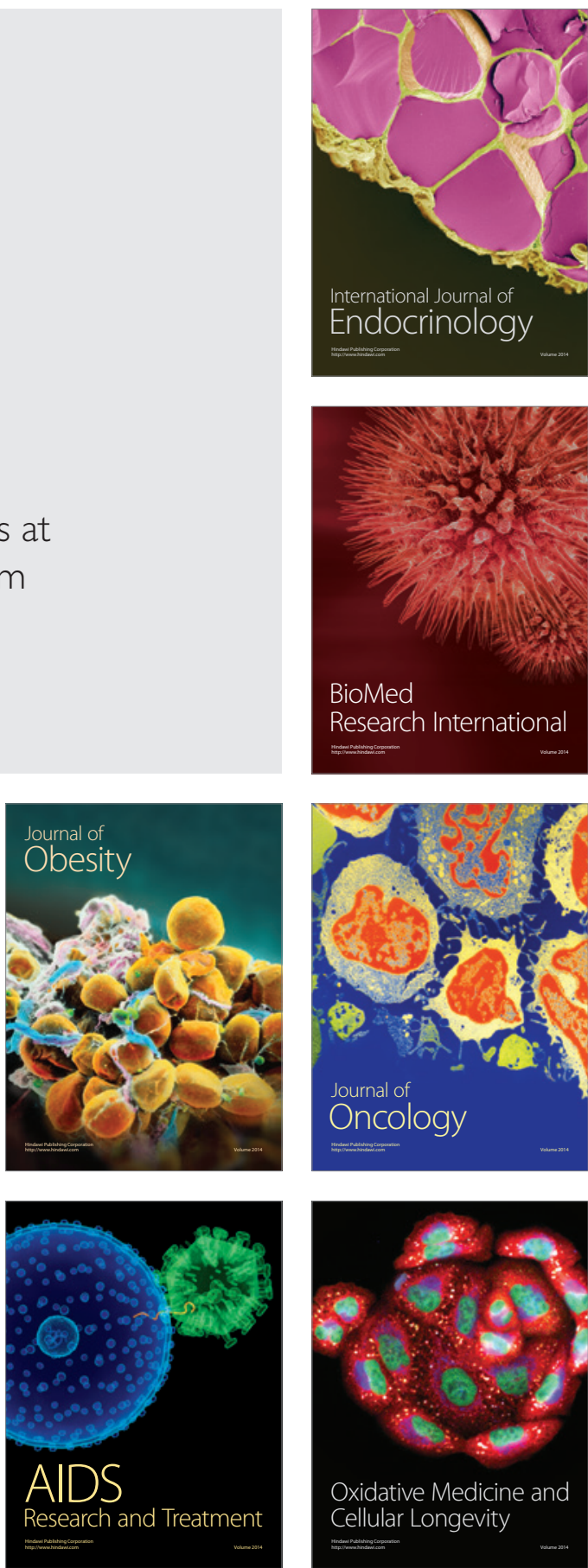